\title{
Structural diversity and electronic properties in potassium silicides
}

Chun-Mei Hao, Yunguo Li, Hong-Mei Huang, and Yan-Ling Li

Citation: The Journal of Chemical Physics 148, 204706 (2018); doi: 10.1063/1.5026699

View online: https://doi.org/10.1063/1.5026699

View Table of Contents: http://aip.scitation.org/toc/jcp/148/20

Published by the American Institute of Physics

\section{Articles you may be interested in}

Constructing first-principles phase diagrams of amorphous $\mathrm{Li}_{x} \mathrm{Si}$ using machine-learning-assisted sampling with an evolutionary algorithm

The Journal of Chemical Physics 148, 241711 (2018); 10.1063/1.5017661

Silicon clathrates for photovoltaics predicted by a two-step crystal structure search Applied Physics Letters 111, 173904 (2017); 10.1063/1.5000444

Neural networks vs Gaussian process regression for representing potential energy surfaces: A comparative study of fit quality and vibrational spectrum accuracy

The Journal of Chemical Physics 148, 241702 (2018); 10.1063/1.5003074

Learning structure-property relationship in crystalline materials: A study of lanthanide-transition metal alloys The Journal of Chemical Physics 148, 204106 (2018); 10.1063/1.5021089

Quantum tunneling of thermal protons through pristine graphene

The Journal of Chemical Physics 148, 204707 (2018); 10.1063/1.5024317

Guest Editorial: Special Topic on Data-Enabled Theoretical Chemistry

The Journal of Chemical Physics 148, 241401 (2018); 10.1063/1.5043213

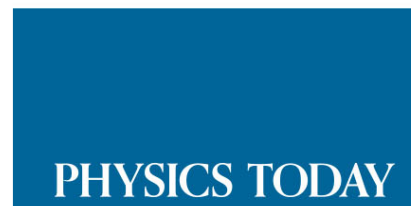




\title{
Structural diversity and electronic properties in potassium silicides
}

\author{
Chun-Mei Hao, ${ }^{1}$ Yunguo $\mathrm{Li}^{2}{ }^{2}$ Hong-Mei Huang, ${ }^{1}$ and Yan-Ling $\mathrm{Li}^{1, \mathrm{a})}$ \\ ${ }^{1}$ School of Physics and Electronic Engineering, Jiangsu Normal University, Xuzhou 221116, China \\ ${ }^{2}$ Department of Earth Sciences, University College London, Gower Street, London WC1E 6BT, United Kingdom
}

(Received 22 February 2018; accepted 9 May 2018; published online 29 May 2018)

\begin{abstract}
Stable potassium silicides in the complete compositional landscape were systematically explored up to $30 \mathrm{GPa}$ using the variable-composition evolutionary structure prediction method. The results show that $\mathrm{K}_{4} \mathrm{Si}, \mathrm{K}_{3} \mathrm{Si}, \mathrm{K}_{5} \mathrm{Si}_{2}, \mathrm{~K}_{2} \mathrm{Si}, \mathrm{K}_{3} \mathrm{Si}_{2}, \mathrm{KSi}, \mathrm{KSi}_{2}, \mathrm{KSi}_{3}$, and $\mathrm{K}_{8} \mathrm{Si}_{46}$ have their stability fields in the phase diagram. The spatial dimensional diversity of polymerized silicon atoms ( $0 \mathrm{D}$ "isolated" anion, dimer, $\mathrm{Si}_{4}$ group, 1D zigzag chain, 2D layer, and 3D network) under the potassium sublattice was uncovered as silicon content increases. Especially, the 2D layered silicon presents interestingly a variety of shapes, such as the " $4+6$ " ring, " $4+8$ "ring, and 8-membered ring. K-Si bonding exhibits a mixed covalency and ionicity, while Si-Si bonding is always of covalent character. Semiconductivity or metallicity mainly depends on the form of sublattices and $\mathrm{K}: \mathrm{Si}$ ratio, which allows us to find more semiconductors in the Si-rich side when closed-shell K cations are encompassed by polymerized $\mathrm{Si}$. The semiconducting silicides present strong absorption in the infrared and visible light range. These findings open up the avenue for experimental synthesis of alkali metal-IVA compounds and potential applications as battery electrode materials or photoelectric materials. Published by AIP Publishing. https://doi.org/10.1063/1.5026699
\end{abstract}

\section{INTRODUCTION}

The family of alkali metal- and alkaline earth metalIVA compounds has been attracting considerable attention recently, not only because of their various extraordinary properties and potential applications but also because they can actually be precursors for novel group-IVA allotropes that cannot be prepared in other ways. ${ }^{1-9}$ The polymerized behavior of carbon or silicon atoms under the framework of alkali metal and alkaline earth metal under pressure has been widely discussed by combined theoretical and experimental studies. ${ }^{3-5,10-15}$ A calcium carbide with a high carbon content could act as a precursor to fabricate a variety of three-dimensional structures of carbon by removing metal atoms. ${ }^{11,16}$ This idea has been successfully applied to design novel allotropes of silicon. Using $\mathrm{Na}_{4} \mathrm{Si}_{24}$ synthesized in the $\mathrm{Na}-\mathrm{Si}$ binary system under high pressure, Kim et al. prepared an open-framework allotrope of silicon, $\mathrm{Si}_{24}$, a semiconductor with a quasi-direct bandgap. ${ }^{6}$ Subsequently, other silicon allotropes were consecutively suggested by removing the guest-free alkali metal atoms theoretically. ${ }^{17,18}$ The success in these systems strongly motivates us to further the search and design of new materials in other alkaline metal-IVA systems.

Although there are plenty of theoretical and experimental studies on the $\mathrm{Li}-\mathrm{Si}^{8,9,19-31}$ and $\mathrm{Na}-\mathrm{Si}$ system, ${ }^{6,17,18}$ study on the $\mathrm{K}-\mathrm{Si}$ system is very limited. For the $\mathrm{K}-\mathrm{Si}$ system, there are three known phases at ambient conditions: $\mathrm{KSi},{ }^{32-34}$ $\mathrm{K}_{12} \mathrm{Si}_{17}{ }^{35}$ and $\mathrm{K}_{8} \mathrm{Si}_{46} \cdot{ }^{36} \mathrm{KSi}$ crystallizes in a cubic $\mathrm{KGe}-$ type structure (space group $P-43 n, 32$ molecules per unit

a)ylli@jsnu.edu.cn cell, i.e., $\mathrm{Z}=32$ ), in which both $\mathrm{K}$ and $\mathrm{Si}$ atoms form tetrahedrons. ${ }^{32,33} \mathrm{KSi}$ can be written as $\mathrm{K}_{4} \mathrm{Si}_{4}$ because of the existence of cluster $\mathrm{Si}_{4}{ }^{4-}$. KSi can absorb hydrogen to form the potassium silanide, $\mathrm{KSiH}_{3}$, a reversible hydrogen storage material. ${ }^{37}$ The reported high-pressure form of tetragonal $\mathrm{KSi}$ is of the $\mathrm{NaPb}$-type (space group $I 4_{1} /$ acd, $\mathrm{Z}=32$ ). ${ }^{34}$ $\mathrm{K}_{12} \mathrm{Si}_{17}$ contains isolated $\mathrm{Si}_{9}{ }^{4-}$ clusters and is a potential precursor candidate for silicon clusters in solution. ${ }^{35}$ In addition, some studies on the $\mathrm{K}-\mathrm{Si}$ system focused on exploring the pressure-induced isostructural volume collapse observed during the phase transition of type I silicon-clathrate. ${ }^{38-40}$ $\mathrm{K}_{8} \mathrm{Si}_{46}$ exhibits an unusual volume collapse transition at about $15 \mathrm{GPa}$, while apparently retaining the same cubic clathrate crystal structure, which is followed by a pressure-induced amorphization above $32 \mathrm{GPa}^{38}$ The isostructural phase transition and reversible amorphization observed in $\mathrm{K}_{8} \mathrm{Si}_{46}$ indicate that there are thermodynamically stable new compounds in the $\mathrm{K}-\mathrm{Si}$ system. Therefore, it is absolutely necessary to perform a complete phase diagram search for stable compounds in the $\mathrm{K}-\mathrm{Si}$ system by using fruitful crystal structural prediction methods.

In this work, the thermodynamic phase diagram of the $\mathrm{K}-\mathrm{Si}$ system in the range of $0-30 \mathrm{GPa}$ is investigated by means of evolutionary algorithm ${ }^{41,42}$ in combination with first-principles total energy calculations. To obtain thermodynamically stable stoichiometries, we perform variable composition structural search in the whole compositional space, which has successfully uncovered novel compounds in many systems. ${ }^{13,43}$ The thermodynamic stability field of predicted compounds is determined via free energy calculations under harmonic approximation. Besides, electronic structures and bonding characteristics are systematically discussed. We find that the Si-rich compounds are semiconductors, except for 
$F d-3 m-\mathrm{KSi}_{2}$ and $P-1-\mathrm{KSi}$, while the $\mathrm{K}$-rich compounds are all metals, except for $P-1-\mathrm{K}_{3} \mathrm{Si}_{2}$ and $R-3 m-\mathrm{K}_{4} \mathrm{Si}$. The $P-1-$ $\mathrm{K}_{3} \mathrm{Si}_{2}$ and $R-3 m-\mathrm{K}_{4} \mathrm{Si}$ are semiconductors with an indirect bandgap.

\section{COMPUTATIONAL METHODS}

Searches for stable structures in the K-Si system under compression were carried out using the evolutionary algorithm USPEX code ${ }^{41,42}$ coupled with the Vienna Ab-initio Simulation Package (VASP) program ${ }^{44}$ based on density functional theory (DFT) within the generalized gradient approximation with the exchange-correlation functional of Perdew-BurkeErnzerhof (PBE). ${ }^{45}$ The electron-ion interaction was depicted by means of the projector-augmented wave (PAW) with $3 p^{6} 4 s^{1}$ and $3 s^{2} 3 p^{2}$ as valence electrons for $\mathrm{K}$ and $\mathrm{Si}$, respectively. The most interesting structures were further relaxed with a basis set cutoff of $350 \mathrm{eV}$. The enthalpy of formation per atom of $\mathrm{K}_{\mathrm{n}} \mathrm{Si}_{\mathrm{m}}$ is defined as $\Delta H_{\mathrm{f}}\left(\mathrm{K}_{\mathrm{n}} \mathrm{Si}_{\mathrm{m}}\right)=\left[H\left(\mathrm{~K}_{\mathrm{n}} \mathrm{S}_{\mathrm{m}}\right)-\mathrm{n} H(\mathrm{~K})-\mathrm{m} H(\mathrm{Si})\right] /(\mathrm{n}$ $+\mathrm{m})$, where all enthalpies $H$ are given at the same pressure and zero temperature. Phonon calculations were performed to determine the dynamical stability of the predicted structures by using the finite displacement approach as implemented in the Phonopy code. ${ }^{46,47}$ The lattice dynamic properties were also checked by the QUANTUM ESPRESSO package ${ }^{48}$ using PAW pseudopotentials with a cutoff energy of $50 \mathrm{Ry}$. The electron localization function $(E L F)^{49}$ was used to analyze the chemical bonds.

\section{RESULTS AND DISCUSSION}

\section{A. Thermodynamic phase diagram}

The evolutionary algorithm USPEX, ${ }^{41,42}$ which can simultaneously find stable stoichiometries and the corresponding structures in multicomponent systems, was used to predict stable K-Si compounds and their structures. In these calculations, all stoichiometries were allowed (with the constraint that the total number of atoms in the unit cell being below 32 atoms), and calculations were performed at $5 \mathrm{GPa}, 10 \mathrm{GPa}$, $20 \mathrm{GPa}$, and $30 \mathrm{GPa}$. The pressure-composition phase diagram of the $\mathrm{K}-\mathrm{Si}$ system is given in Fig. 1(a). In our calculations, we also included an identified phase $\mathrm{K}_{8} \mathrm{Si}_{46} \cdot{ }^{38,39}$ As shown in Fig. 1(a), the K-Si compounds located on the convex hull are thermodynamically stable against decomposition to any other binaries or the elements, while the compounds above the convex hull are metastable. Consequently, we found that $\mathrm{K}_{4} \mathrm{Si}$, $\mathrm{K}_{3} \mathrm{Si}, \mathrm{K}_{5} \mathrm{Si}_{2}, \mathrm{~K}_{2} \mathrm{Si}, \mathrm{K}_{3} \mathrm{Si}_{2}, \mathrm{KSi}, \mathrm{KSi}_{2}, \mathrm{KSi}_{3}$, and $\mathrm{K}_{8} \mathrm{Si}_{46}$ have thermodynamic stability fields on the phase diagram: $\mathrm{K}_{4} \mathrm{Si}$, stable above $9 \mathrm{GPa} ; \mathrm{K}_{3} \mathrm{Si}$, stable above $20 \mathrm{GPa} ; \mathrm{K}_{5} \mathrm{Si}_{2}$, stable above $6.5 \mathrm{GPa}$ to $28.5 \mathrm{GPa} ; \mathrm{K}_{2} \mathrm{Si}$, stable above $12.5 \mathrm{GPa}$; $\mathrm{K}_{3} \mathrm{Si}_{2}$, stable above $15 \mathrm{GPa}$ to $27.5 \mathrm{GPa}$; $\mathrm{KSi}$, stable from 0 to $22.5 \mathrm{GPa} ; \mathrm{KSi}_{2}$, stable above $18.5 \mathrm{GPa} ; \mathrm{KSi}_{3}$, stable from 2.5 to $19.5 \mathrm{GPa}$; and $\mathrm{K}_{8} \mathrm{Si}_{46}$, stable from 0 to $17.5 \mathrm{GPa}$ [see Fig. 1(b)]. For all the newly predicted structures, calculated phonon dispersion curves confirmed their dynamical stability (see Fig. 2 and Figs. S2 and S3 of the supplementary material).

As expected, we found that the upper limit of stability domain of $\mathrm{K}_{8} \mathrm{Si}_{46}(\sim 17.5 \mathrm{GPa})$ agrees well with its isostructural phase transition pressure $(\sim 15 \mathrm{GPa})$ observed experimentally. ${ }^{38}$ Therefore, one can conclude that the volume collapse and amorphization of $\mathrm{K}_{8} \mathrm{Si}_{46}$ are closely related to the change of thermodynamic stability under strong compression. Theoretically, $\mathrm{K}_{8} \mathrm{Si}_{46}$ decomposed to $\mathrm{KSi}_{3}$ (from 17.5 to $19.0 \mathrm{GPa}$ ) and $s H$-silicon (simple hexagonal phase of silicon) or $\mathrm{KSi}_{2}$ (above $20 \mathrm{GPa}$ ) and $s H$-silicon above $17.5 \mathrm{GPa}$.

In addition, we found that some $\mathrm{K}-\mathrm{Si}$ compounds can undergo a series of structural phase transitions within the considered pressure range [see Fig. 1(b)]. The $P-1-\mathrm{K}_{2} \mathrm{Si}$

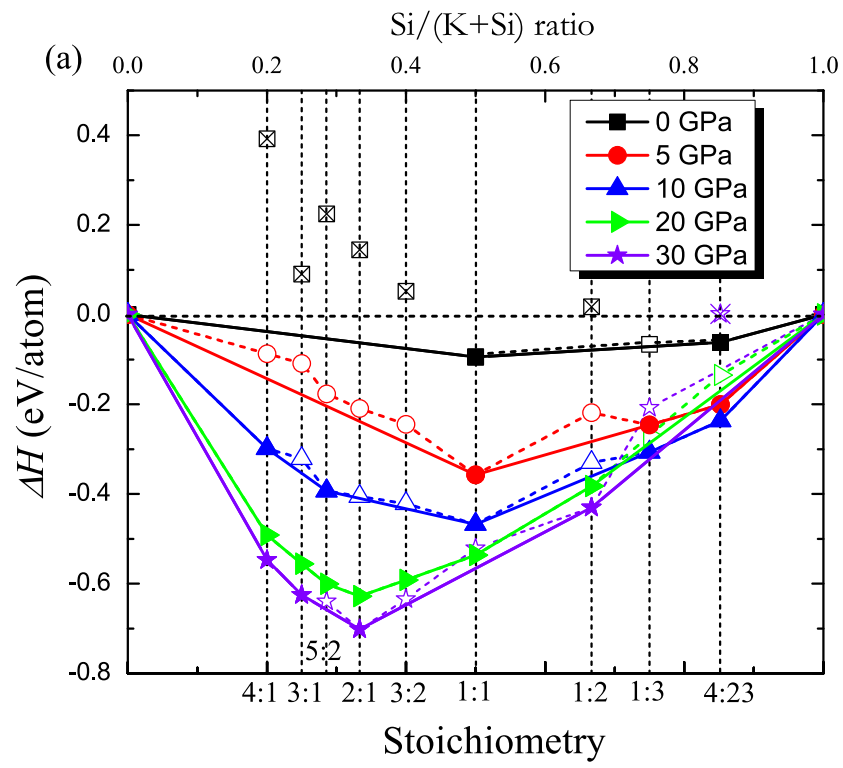

(b)

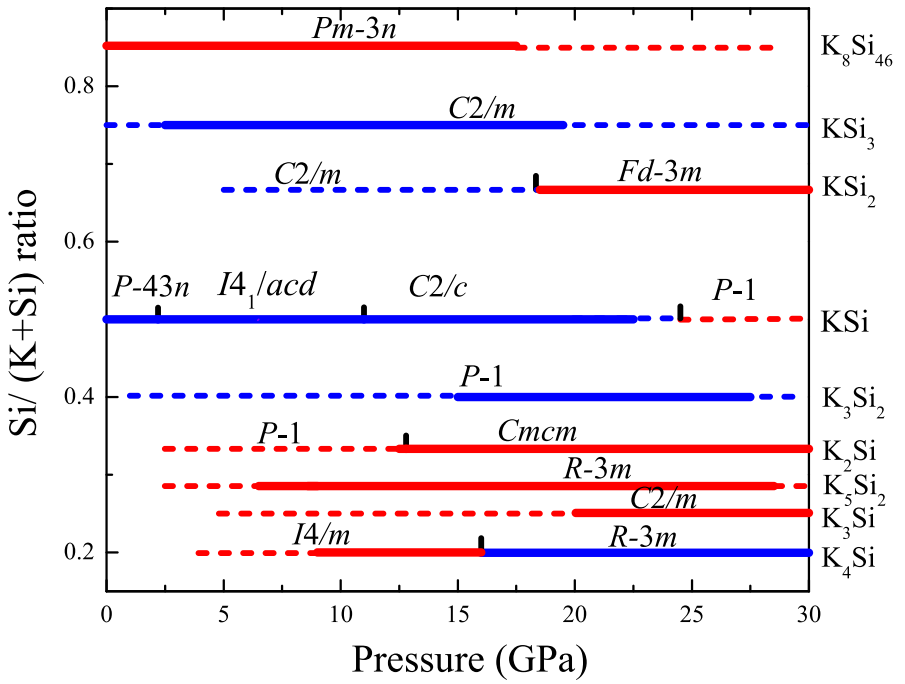

FIG. 1. (a) Convex hull diagram for the K-Si system at examined pressures. (b) Pressure-composition phase diagram of the K-Si system. Thick solid lines represent thermodynamically stable phases and dashed lines represent the metastable ones (red lines represent the metal and blue lines represent the semiconductor). 

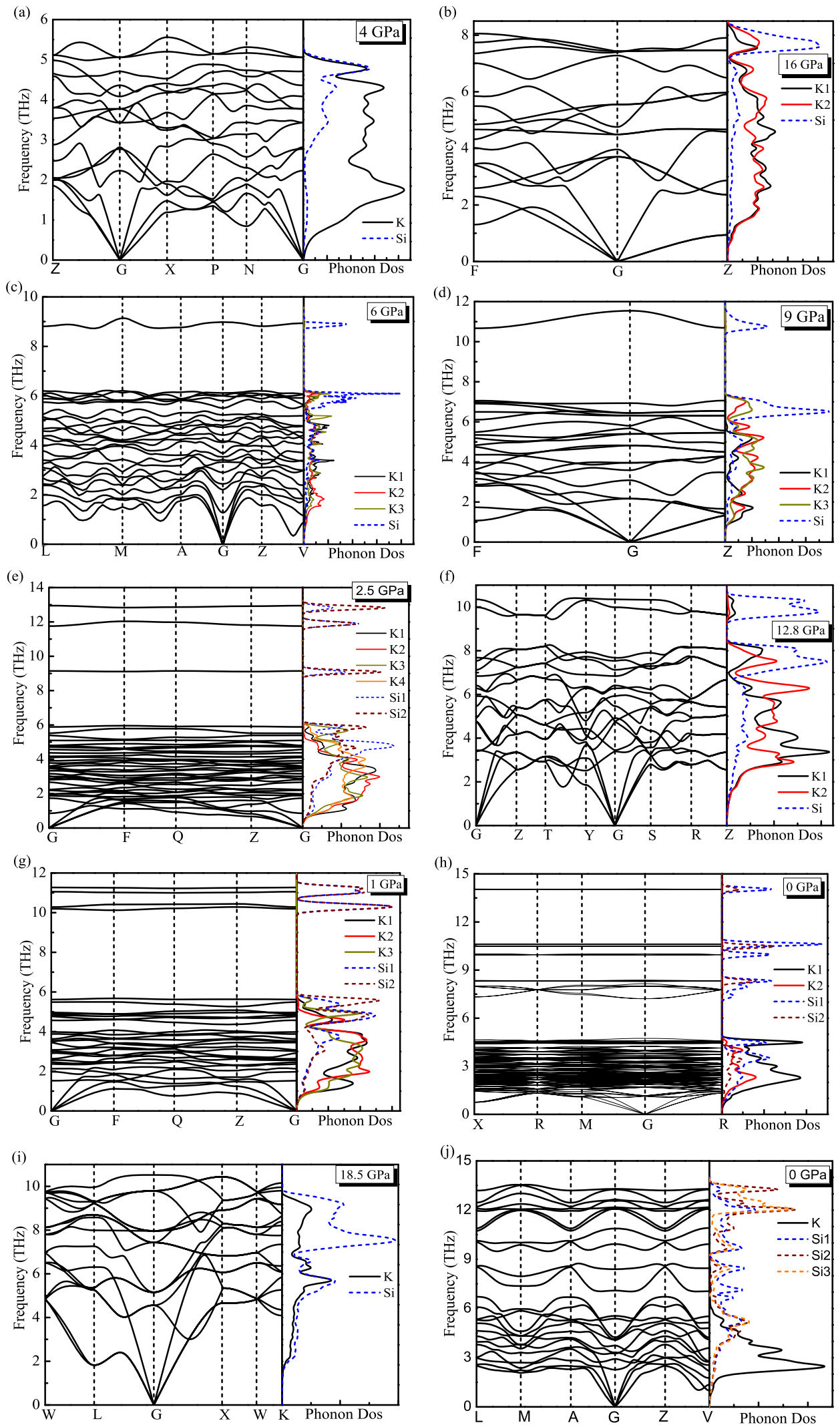
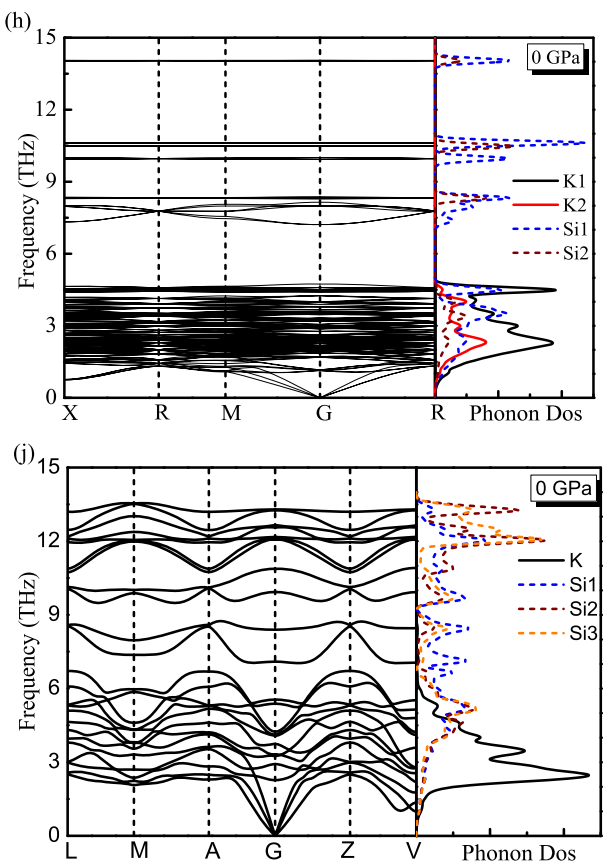

FIG. 2. Phonon dispersion curves and partial atomic phonon density of states (phonon DOSs) of (a) $I 4 / m-\mathrm{K}_{4} \mathrm{Si}$, (b) $R-3 m-\mathrm{K}_{4} \mathrm{Si}$, (c) $C 2 / m-\mathrm{K}_{3} \mathrm{Si}$, (d) $R-3 m-$ $\mathrm{K}_{5} \mathrm{Si}_{2}$, (e) $P-1-\mathrm{K}_{2} \mathrm{Si}$, (f) $C m c m-\mathrm{K}_{2} \mathrm{Si}$, (g) $P-1-\mathrm{K}_{3} \mathrm{Si}_{2}$, (h) $P-43 n-\mathrm{KSi}$, (i) $F d$ $3 m-\mathrm{KSi}_{2}$, and (j) $C 2 / m-\mathrm{KSi}_{3}$ at examined pressures. transformed into the orthorhombic $\mathrm{Cmcm}-\mathrm{K}_{2} \mathrm{Si}$ at $12.8 \mathrm{GPa}$. In the case of KSi, the $P-43 n-\mathrm{KSi}$ transformed to the $I 4_{1} /$ acd $\mathrm{KSi}$ at $2.2 \mathrm{GPa}$ and to the $C 2 / \mathrm{c}-\mathrm{KSi}$ at $11 \mathrm{GPa}$, followed by the $P-1-\mathrm{KSi}$ at $24.5 \mathrm{GPa}$ (see Fig. S1 of the supplementary material). The monoclinic $C 2 / m-\mathrm{KSi}_{2}$ transformed into the cubic $\mathrm{Fd}-3 m-\mathrm{KSi}_{2}$ at $18.5 \mathrm{GPa}$.

\section{B. Dynamical and structural properties}

To confirm the dynamical stability of the predicted compounds, we calculated the phonon spectra along the highsymmetry directions in the Brillouin zone (BZ) at corresponding pressures. One can conclude that the predicted compounds 
together with the well-known $\mathrm{K}_{8} \mathrm{Si}_{46}$ are dynamically stable within their thermodynamic-stability pressure domain since there is no imaginary frequency in the calculated phonon spectra, as shown in Fig. 2 and Figs. S2 and S3 of the supplementary material. From the partial atomic phonon density of states (PHDOSs), Si atoms almost dominate the whole frequency range, but with a slight emphasis relatively on the high-frequency modes, whereas $\mathrm{K}$ atoms dominate relatively the low frequency modes because of its relatively large atomic mass. For the K-rich side, including $\mathrm{KSi}$, there are larger frequency gaps in the optical branches part because of the peculiar polymerization form of silicon atoms (0D, 1D and 2D, see Figs. 2 and 3 and Figs. S2 and S3 of the supplementary material), which in nature originates from the chemical bonding network topology, i.e. links between the Si sublattice and $\mathrm{K}$ sublattice. Generally, PHDOS of Si hovers over the highfrequency region if there is direct bonding of covalent character between $\mathrm{Si}$ atoms, which propagates into the lower-frequency region if there is abundant direct bonding of ionic character between $\mathrm{Si}$ and $\mathrm{K}$ or $\mathrm{Si}$ is isolated by $\mathrm{K}$.

All stable structures of the $\mathrm{K}-\mathrm{Si}$ system are plotted in Fig. 3. The equilibrium lattice parameters of the predicted (a)

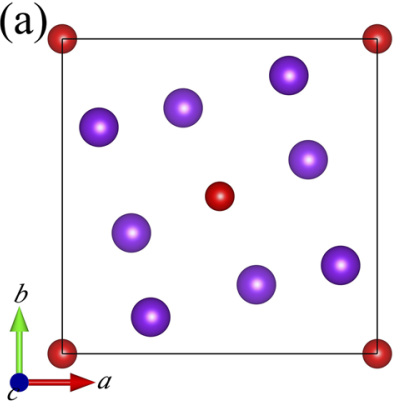

(e)

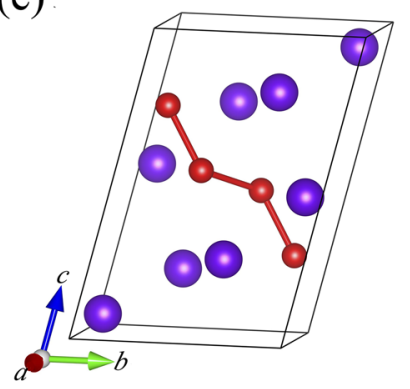

(i)

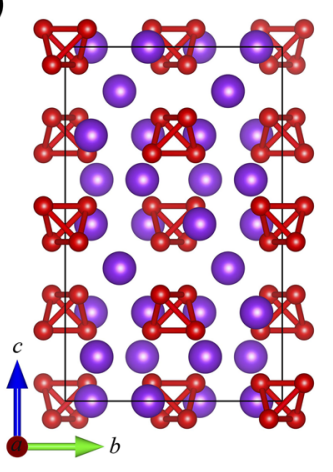

(m)

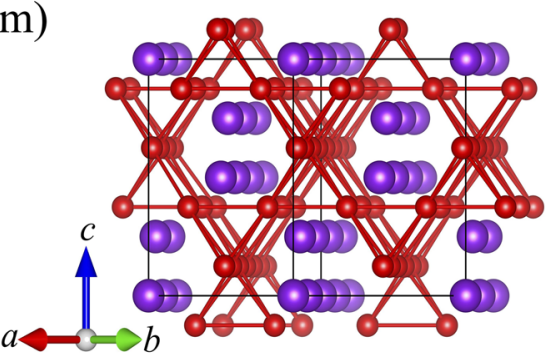

(b)

(f)

(j)
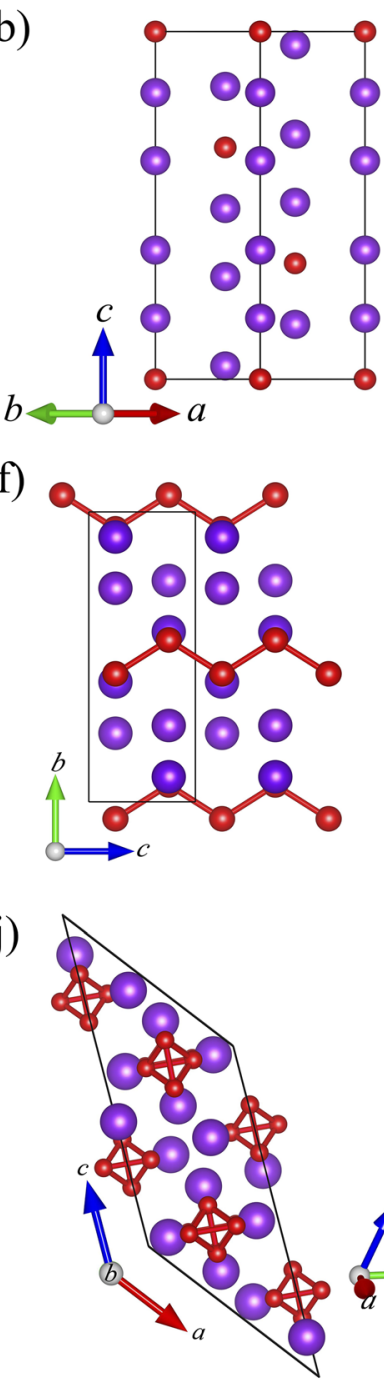

(n)

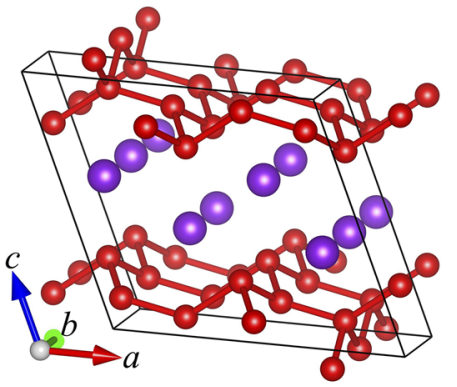

(c)

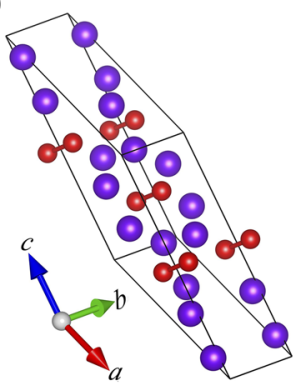

(g)

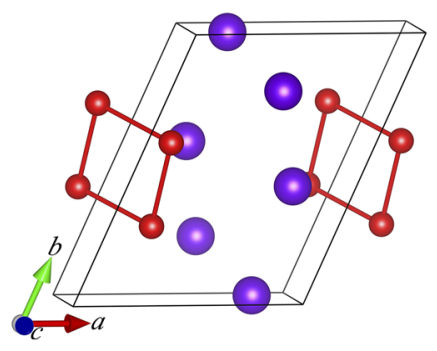

(k) (d)

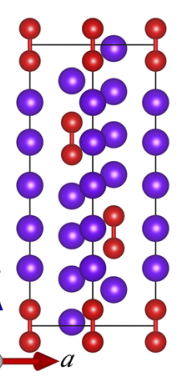

(h)

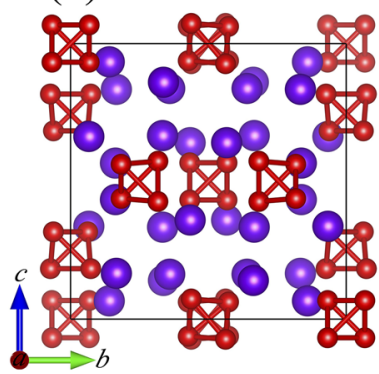

(1)

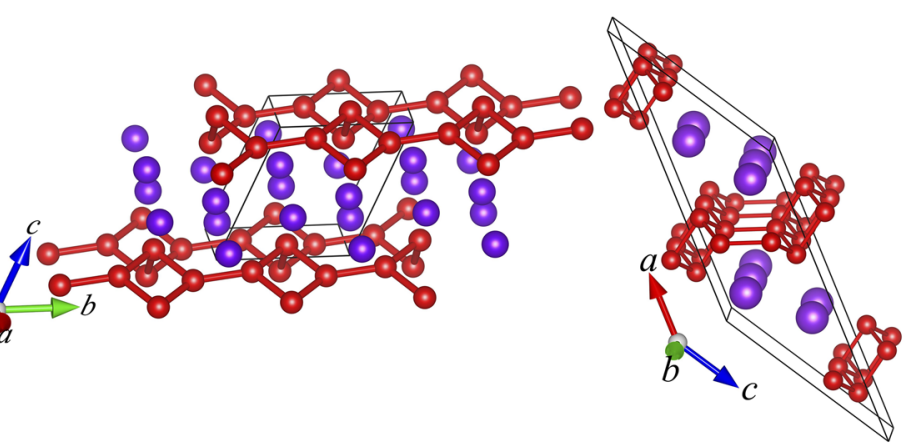

(o)

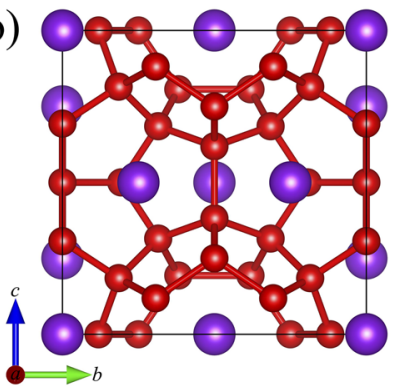

FIG. 3. Crystal structures of K-Si compounds. (a) $I 4 / m-\mathrm{K}_{4} \mathrm{Si}$, (b) $R-3 m-\mathrm{K}_{4} \mathrm{Si}$, (c) $C 2 / m-\mathrm{K}_{3} \mathrm{Si}$, (d) $R-3 m-\mathrm{K}_{5} \mathrm{Si} 2$, (e) $P-1-\mathrm{K}_{2} \mathrm{Si}$, (f) $C m c m-\mathrm{K}_{2} \mathrm{Si}$, (g) $P-1-\mathrm{K}_{3} \mathrm{Si}{ }_{2}$, (h) $P-43 n-\mathrm{KSi}$, (i) $I 4_{1} / a c d-\mathrm{KSi}$, (j) $C 2 / c-\mathrm{KSi}$, (k) $P-1-\mathrm{KSi}$, (1) $C 2 / m-\mathrm{KSi}_{2}$, (m) $F d-3 m-\mathrm{KSi}_{2}$, (n) $C 2 / m-\mathrm{KSi}_{3}$, and (o) $P m-3 n-\mathrm{K}_{8} \mathrm{Si}_{46}$. 
phases at examined pressures are given in Table S1 of the supplementary material. We find that the silicon sublattices within all predicted silicide phases have a close correlation with the K:Si ratio (see Fig. 3). Similar to our previous study on the $\mathrm{Ca}-\mathrm{C}$ system, ${ }^{3,4,13}$ the polymerization of silicon atoms underwent great changes with the increasing silicon content; that is, isolated silicon atoms are polymerized, in turn, into $\mathrm{Si}_{2}$ dumbbells, $\mathrm{Si}_{4}$ groups, chains, layers, and threedimensional framework structures (see Figs. 3 and 4). Let us discuss the predicted phases in order of the increasing silicon content.

$\mathbf{K}_{4}$ Si. It is thermodynamically stable (metastable between $4 \mathrm{GPa}$ and $9 \mathrm{GPa}$ ) above $9 \mathrm{GPa}$ [space group $\mathrm{I} / \mathrm{m}(\mathrm{Z}=2)$ ]. The tetragonal $\mathrm{K}_{4} \mathrm{Si}$ with $I 4 / m$ symmetry [see Fig. 3(a)] is thermodynamically stable up to about $16 \mathrm{GPa}$. The "isolated" $\mathrm{Si}$ atoms occupy the crystallographic $2 b$ sites, while alkali metal atoms hold $8 h$ sites (see Table $\mathrm{S} 1$ of the supplementary material). The tetragonal structure of $\mathrm{K}_{4} \mathrm{Si}$ has been observed in $\mathrm{Li}_{4} \mathrm{C}^{10}$ and has also been favored by highly compressed $\mathrm{Li}_{4} \mathrm{Si}^{31}$ Above $16 \mathrm{GPa}$, the semi-metallic $I 4 / m-\mathrm{K}_{4} \mathrm{Si}$ gives way to the semiconducting $R-3 m-\mathrm{K}_{4} \mathrm{Si}$ [see Fig. 3(b)], in which the "isolated" $\mathrm{Si}$ atom is surrounded by eight $\mathrm{K}$ atoms (i.e., eight-fold coordinated silicon).

$\mathbf{K}_{3} \mathrm{Si}$. The monoclinic structure of $\mathrm{K}_{3} \mathrm{Si}$ [space group $C 2 / m, \mathrm{Z}=4$, Fig. 3(c)] is predicted to be thermodynamically stable above $20 \mathrm{GPa}$ (the metastable one between 4.8 and $20 \mathrm{GPa}$ ). Both $\mathrm{Si}$ atoms and $\mathrm{K}$ atoms occupy the $4 i$ sites (Table $\mathrm{S} 1$ of the supplementary material). The $\mathrm{Si}-\mathrm{Si}$ bond length in the "isolated" dumbbell is $2.502 \AA$ at $6 \mathrm{GPa}$.

$\mathbf{K}_{5} \mathbf{S i}_{2} \cdot \mathrm{K}_{5} \mathrm{Si}_{2}$ dominates the range of pressure from $6.5 \mathrm{GPa}$ to $28.5 \mathrm{GPa}$, adopting $R-3 m$ symmetry [Z $=1$, Fig. 3(d)], in which $\mathrm{Si}$ atoms occupy the crystallographic $2 c$ sites. The structural feature of $R-3 m-\mathrm{K}_{5} \mathrm{Si}_{2}$ is identical to
$R-3 m-\mathrm{Li}_{5} \mathrm{Si}_{2},{ }^{31}$ in which the silicon dumbbell (bond length, $2.389 \AA$ at $9 \mathrm{GPa}$ ) is arranged along the $c$-axis. It is worth noting that a ratio of $5: 2$ is also favored in the $\mathrm{Li}-\mathrm{Sn}^{50}$ and $\mathrm{Ca}-\mathrm{C}$ systems. ${ }^{13}$ The results indicate that the component ratio of $5: 2$ is a favorable one for group IA-IVA or IIA-IVA compounds.

$\mathbf{K}_{2}$ Si. Triclinic $P-1-\mathrm{K}_{2} \mathrm{Si}[\mathrm{Z}=4$, Fig. 3(e)] stabilizes in a narrow pressure range of $12.5 \mathrm{GPa}-12.8 \mathrm{GPa}$. Structurally, it includes zigzag $\mathrm{Si}_{4}$ groups in which the bond lengths are $2.314 \AA$ and $2.350 \AA$ and the bond angle is about $125.81^{\circ}$ at $2.5 \mathrm{GPa}$. Upon compression, the triclinic $P-1-\mathrm{K}_{2} \mathrm{Si}$ transforms into an orthorhombic Cmcm- $\mathrm{K}_{2} \mathrm{Si}[\mathrm{Z}=4$, Fig. 3(f)] at $12.8 \mathrm{GPa}$. The $\mathrm{Si}$ atoms in the $\mathrm{Cmcm}-\mathrm{K}_{2} \mathrm{Si}$ phase are aggregated into zigzag chains. It is surprising that there is an abnormal extension in $\mathrm{Si}-\mathrm{Si}$ bond length compared to the lowpressure $P-1$ phase. At $12.8 \mathrm{GPa}$, the bond length of $\mathrm{Si}-\mathrm{Si}$ in silicon atomic chains is about $2.522 \AA$ and the $\mathrm{Si}-\mathrm{Si}-\mathrm{Si}$ angle is $113.99^{\circ}$.

$\mathbf{K}_{3} \mathbf{S i}_{2} \cdot \mathrm{K}_{3} \mathrm{Si}_{2}$ crystallizes in the $P-1$ structure $[\mathrm{Z}=2$, Fig. 3(g)] and is thermodynamically stable from $15 \mathrm{GPa}$ to 27.5 GPa. Si atoms form a parallelogram with the bond lengths of $2.400 \AA$ and $2.404 \AA$ and the Si-Si-Si angle of $90.427^{\circ}$ and $89.570^{\circ}$ at $1.0 \mathrm{GPa}$.

KSi. KSi has three thermodynamically stable phases $\left(P-43 n, I 4_{1} / a c d\right.$, and $\left.C 2 / c\right)$. The well-known cubic $P-43 n-$ $\mathrm{KSi}^{32}[\mathrm{Z}=32$, Fig. 3(h)] is reproduced in our structure searches at ambient pressure. The optimized lattice parameter $(12.733 \AA)$ agrees well with the experimental data $(12.620 \AA) .{ }^{32,33}$ Two nonequivalent $\mathrm{Si}$ atoms locate at the $24 i$ $(0.562,0.073,0.183)$ and $8 e(0.568,0.568,0.568)$ sites, respectively. Si1 atoms form slightly distorted tetrahedrons with two different Si-Si bond lengths (2.428 $\AA$ and $2.447 \AA$ ) at ambient pressure, while $\mathrm{Si} 2$ atoms form regular tetrahedrons with a bond length of $2.435 \AA$ at ambient pressure [see Fig. 4(h)]. We (a)

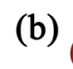

(c)

(f)

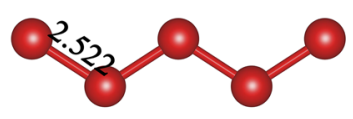

(i)

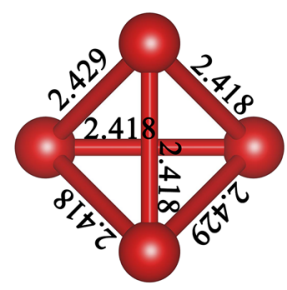

(1)

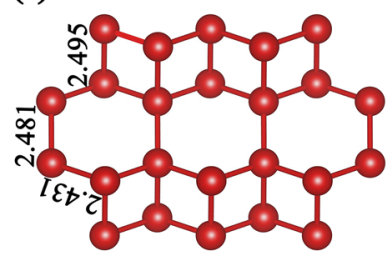

(g)

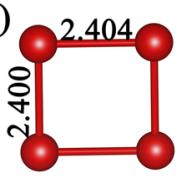

(j)

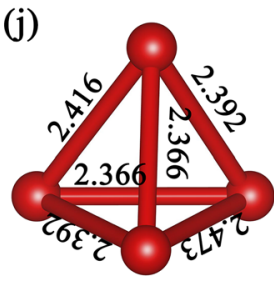

(m)

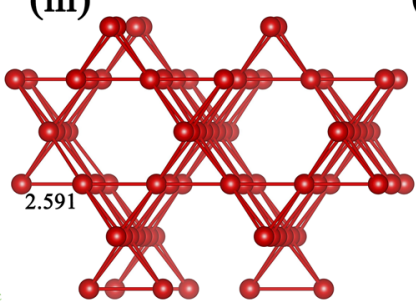

(h)

(k) (e)

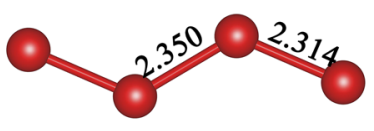

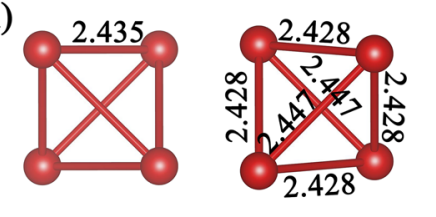

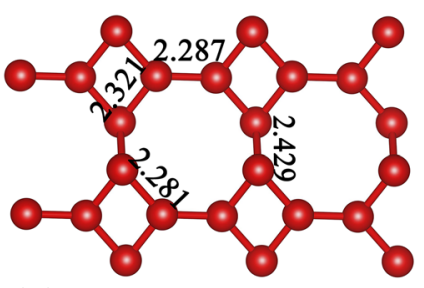

(n)

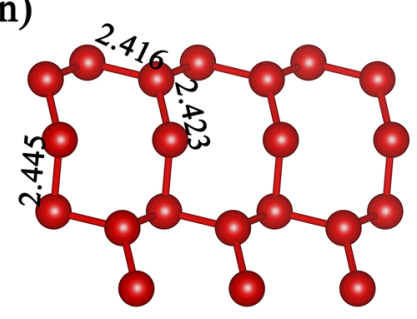

FIG. 4. Silicon patterns in the K-Si system at examined pressures. Bond length is in $\AA$. (a) $I 4 / m-\mathrm{K}_{4} \mathrm{Si}$ at $4 \mathrm{GPa}$, (b) $R-3 m-\mathrm{K}_{4} \mathrm{Si}$ at $16 \mathrm{GPa}$, (c) $C 2 / m-$ $\mathrm{K}_{3} \mathrm{Si}$ at $6 \mathrm{GPa}$, (d) $R-3 m-\mathrm{K}_{5} \mathrm{Si}_{2}$ at 9.0 $\mathrm{GPa}$, (e) $P-1-\mathrm{K}_{2} \mathrm{Si}$ at $2.5 \mathrm{GPa}$, (f) $\mathrm{Cmcm}-$ $\mathrm{K}_{2} \mathrm{Si}$ at $12.8 \mathrm{GPa}$, (g) $P-1-\mathrm{K}_{3} \mathrm{Si}_{2}$ at $1 \mathrm{GPa}$, (h) $P-43 n-\mathrm{KSi}$ at $0 \mathrm{GPa}$, (i) $I 4_{1} /$ acd $-\mathrm{KSi}$ at $2.2 \mathrm{GPa}$, (j) $C 2 / c-\mathrm{KSi}$ at $11 \mathrm{GPa}$, (k) $P-1-\mathrm{KSi}$ at $24.5 \mathrm{GPa}$, (1) $C 2 / m-\mathrm{KSi}_{2}$ at $5 \mathrm{GPa},(\mathrm{m}) \mathrm{Fd}-3 m-\mathrm{KSi}_{2}$ at $18.5 \mathrm{GPa}$, and (n) $C 2 / m-\mathrm{KSi}_{3}$ at 0 GPa. 
performed some component-fixed calculations (at the selected pressure points of $5 \mathrm{GPa}$ and $10 \mathrm{GPa}$ ) with the constraint that the number of $\mathrm{K}_{4} \mathrm{Si}_{4}$ in the unit cell is up to 4 formulas (that is, at most 32 atoms in the unit cell). It turns out that the $\mathrm{NaPb}$-type structure was reproduced in our searching. The $\mathrm{NaPb}$-type structure (space group $\mathrm{I}_{1} /$ acd), with isolated $\mathrm{Si}_{4}$ tetrahedra [Si-Si bond lengths are $2.418 \AA$ and $2.429 \AA$, see Fig. 4(i)] surrounded by $\mathrm{K}$ atoms [see Fig. 3(i)], is thermodynamically stable at the pressure range from $2.2 \mathrm{GPa}$ to $11 \mathrm{GPa}$. The predicted phase transition pressure of $2.2 \mathrm{GPa}$ from $P-43 n$ phase to $I 4_{1} /$ acd phase is in good agreement with the experimental data (about $4 \mathrm{GPa}$ ). ${ }^{34}$ The tetragonal $\mathrm{NaPb}$-type structure transformed into a monoclinic $C 2 / \mathrm{c}$ structure at the pressure of $11 \mathrm{GPa}$, in which the silicon tetrahedrons (the mean $\mathrm{Si}-\mathrm{Si}$ bond length is $2.401 \AA$ ) were kept [see Figs. 3(j) and 4(j)]. Thus, isolated silicon tetrahedra are still stable up to $24.5 \mathrm{GPa}$ in the KSi compounds. Above $24.5 \mathrm{GPa}, P-1-\mathrm{KSi}(\mathrm{Z}=4)$ becomes thermodynamically metastable. It has an interesting layered structure consisting of alternating layers of $\mathrm{K}$ atoms and $\mathrm{Si}$ atoms [see Fig. 3(k)]. In the silicon layer, the 4-membered rings share a $\mathrm{Si}-\mathrm{Si}$ bond with four neighbor congeners, constructing a "4 + 8"ring pattern, in which $\mathrm{Si}-\mathrm{Si}$ bond lengths are between $2.281 \AA$ and $2.429 \AA$ at $24.5 \mathrm{GPa}$ [see Figs. 3(k) and $4(\mathrm{k})]$.

$\mathbf{K S i}_{2}$. The monoclinic $C 2 / m-\mathrm{KSi}_{2}[\mathrm{Z}=4$, Fig. 3(1)] is thermodynamically metastable at the range of pressure from 5.0 $\mathrm{GPa}$ to $18.5 \mathrm{GPa}$. Different from the silicon layer revealed in $P-1-\mathrm{KSi}, \mathrm{Si}$ atoms in $C 2 / m-\mathrm{KSi}_{2}$ polymerize into a novel layer structure, in which the neighbor silicon stripes with 4-membered rings are welded by the shared $\mathrm{Si}-\mathrm{Si}$ bonds, presenting the wrinkled " $4+6$ " ring pattern [the $\mathrm{Si}-\mathrm{Si}$ bond lengths are between $2.431 \AA$ and $2.495 \AA$ at $5 \mathrm{GPa}$; see Fig. 4(1)]. Differing from the heavier congener $\mathrm{KPb}_{2}$ with the hexagonal Laves phase $\mathrm{MgZn}_{2}$-type structure ${ }^{51}$ (space group $P 6_{3} / m m c, Z=4$ ) at ambient pressure, the thermodynamically stable $\mathrm{KSi}_{2}$ crystallized in the cubic Laves phase $\mathrm{MgCu}_{2}$-type structure ${ }^{52}$ [space group $F d-3 m, \mathrm{Z}=8$, Fig. 3(m)] above $18.5 \mathrm{GPa}$. In the $\mathrm{MgCu}_{2}$-type structure of $\mathrm{KSi}_{2}$, silicon atoms aggregate into the three-dimensional framework structure with the $\mathrm{K}$ atoms running through the tunnels (structurally, $\mathrm{K}$ atoms form zigzag chains.). The neighboring silicon tetrahedrons are hinged by a shared silicon atom [six-fold coordinated silicon observed, Fig. 4(m)], constructing a strong covalent network and thus bringing about a strong incompressibility of this system. The pressure-induced structural modification from the monoclinic $C 2 / m$ structure to the cubic $F d-3 m$ leads to a counter-intuitive chemical bond expansion phenomenon for Si-Si bonds. The Si-Si bond length in Fd-3m at $18.5 \mathrm{GPa}$ is $2.591 \AA$, which is longer than that in the low-pressure $C 2 / m-\mathrm{KSi}_{2}$.

$\mathbf{K S i}_{3}$. The Si-rich $C 2 / m-\mathrm{KSi}_{3}[\mathrm{Z}=4$, Fig. 3(n)] is thermodynamically stable above $2.5 \mathrm{GPa}$ (metastable below $2.5 \mathrm{GPa}$ ). Three inequivalent $\mathrm{Si}$ atoms locate at three $4 i$ sites, forming a wrinkled two-dimension layer with silicon 8-membered rings. At zero pressure, the $\mathrm{Si}-\mathrm{Si}$ bond length is between $2.416 \AA$ and $2.445 \AA$ [Fig. 4(n)].

$\mathbf{K}_{8} \mathrm{Si}_{46}$. The known cubic $\mathrm{K}_{8} \mathrm{Si}_{46}$ [space group $P m-3 n$, $\mathrm{Z}=1$, Fig. $3(\mathrm{o})]$ is thermodynamically stable below $17.5 \mathrm{GPa}$.
It belongs to cage-type structures composed of face-sharing silicon polyhedra of $\mathrm{Si}_{20}$ and $\mathrm{Si}_{24}$, strictly analogous to the well-known gas or liquid hydrates, such as $8 \mathrm{Cl}_{2} \bullet 46 \mathrm{H}_{2} \mathrm{O} .^{36}$ Two small $\mathrm{Si}_{20}$ cages and six large $\mathrm{Si}_{24}$ cages offer the eight sites for guest $\mathrm{K}$ atoms.

\section{Electronic properties}

To understand the electronic properties of K-Si compounds predicted here, we calculated the electronic band structures and density of states (DOSs) (Fig. 5 and Figs. S4 and S5 of the supplementary material). In the Si-rich systems, all the structures are semiconductors, except for $P$ $1-\mathrm{KSi}$ and $F d-3 m-\mathrm{KSi}_{2}$. At the K-rich side, all compounds predicted here exhibit some metallicity, except $R-3 m-\mathrm{K}_{4} \mathrm{Si}$ (an indirect gap of $0.68 \mathrm{eV}$ ) and $P-1-\mathrm{K}_{3} \mathrm{Si}_{2}$ (a direct gap of $0.59 \mathrm{eV})$.

From the DOS plots in Fig. 5, we can clearly see a strong hybridization of $s, p$, and $d$ orbitals of $\mathrm{K}$ for all structures and also a hybridization between $\mathrm{K}$ orbitals and $\mathrm{Si}-p$ orbitals. This is a common feature shared by alkali metal compounds under high pressures. The semiconductivity or metallicity depends on the topology of Si sublattice and K:Si ratio. Due to a much larger electronegativity, $\mathrm{Si}$ gains electrons from $\mathrm{K}$. The chemical bonding between $\mathrm{Si}$ and $\mathrm{K}$ is a mixture of covalency and iconicity, as shown by ELFs in Fig. S6 of the supplementary material. Between Si atoms, it is of covalent characteristic. In K-rich compounds, the Si sublattice needs more electrons from $\mathrm{K}$ besides the limited shared electrons between $\mathrm{Si}$ atoms themselves to fill its $3 p$ orbitals; if filled like in $R-3 m-\mathrm{K}_{4} \mathrm{Si}$, the compound shows semiconducting; otherwise like in $I 4 / m-\mathrm{K}_{4} \mathrm{Si}$, it will be metallic. And in K-rich compounds, most of them are metallic because the semiconductivity asks for an appropriate $\mathrm{Si}$ sublattice under a specific K:Si ratio, in order to completely fulfill Si- $p$ orbitals and produce a closed-shell $\mathrm{K}$. The same argument also applies to Si-rich compounds. However, in Si-rich environment, K can be easily stripped off electrons and surrounded by the $\mathrm{Si}$ sublattice with covalent character like $C 2 / m-\mathrm{KSi}_{3}$. Therefore, most Si-rich compounds are semiconductors. $F d-3 m-\mathrm{KSi}_{2}$ is metallic because a $\mathrm{K}-\mathrm{K}$ bonding network exists between $\mathrm{Si}$ layers.

In the same stoichiometry, the electronic structure can be subjected to metal-semiconductor changes due to the structural evolution and reorganization. The $P-43 n-\mathrm{KSi}$, an indirect semiconductor with a bandgap of $1.24 \mathrm{eV}$ at $0 \mathrm{GPa}$, first transforms into the semiconducting $I 4_{1} /$ acd-KSi at $2.2 \mathrm{GPa}$ (an indirect bandgap of $1.31 \mathrm{eV}$ ) and then into the semiconducting $C 2 / c$ structure at $11 \mathrm{GPa}$ (a direct bandgap of $1.48 \mathrm{eV})$. The $C 2 / c$-KSi transforms into the metallic $P-1-\mathrm{KSi}$ above $24.5 \mathrm{GPa}$. The $C 2 / m-\mathrm{KSi}_{2}$ is a narrow gap semiconductor with an indirect bandgap of $0.23 \mathrm{eV}$ at $5 \mathrm{GPa}$. Upon compression, the semiconducting $C 2 / m-\mathrm{KSi}_{2}$ transforms into the metallic $F d-3 m-\mathrm{KSi}_{2}$ at $18.5 \mathrm{GPa}$. The $C 2 / m-\mathrm{KSi}_{3}$ holds an indirect bandgap of $0.80 \mathrm{eV}$ at $0 \mathrm{GPa}$. There is also a metal-semiconductor transition in $\mathrm{K}_{4} \mathrm{Si}$, and similarly, such a transition was also observed in an isoelectronic compound $\mathrm{Ca}_{2} \mathrm{C} .{ }^{13}$ Differing from the two-dimensional metallicity in the metallic phase of $\mathrm{Ca}_{2} \mathrm{C}, I 4 / m-\mathrm{K}_{4} \mathrm{Si}$ is a semimetal due to a very small overlap between the bottom of the conduction band 
(a)
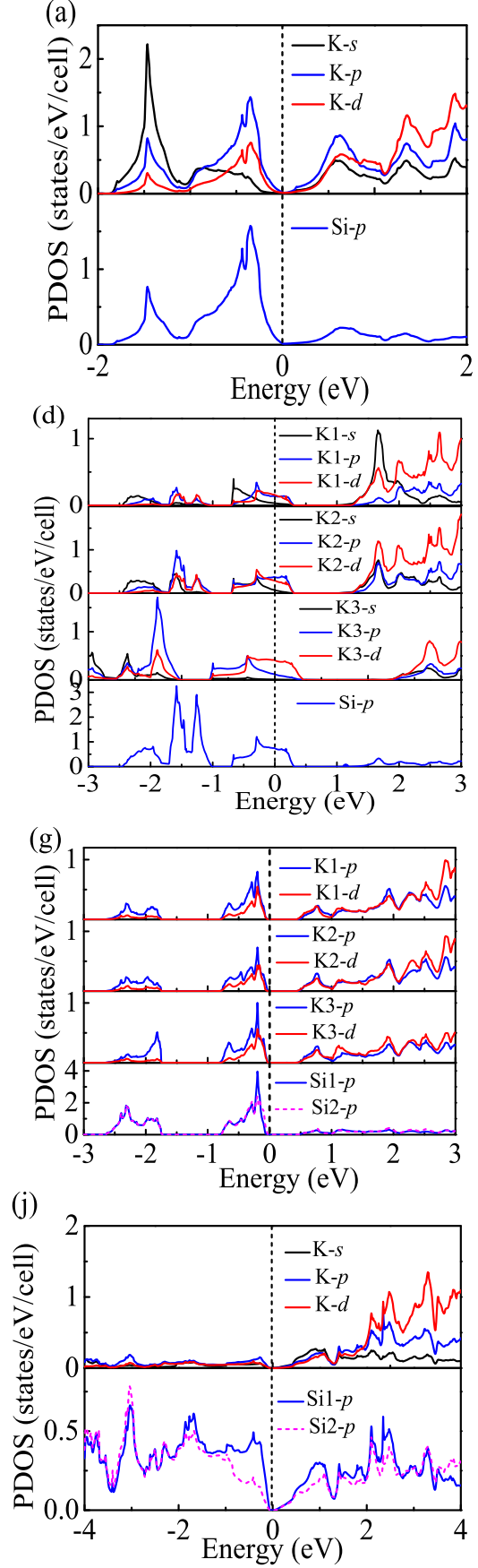

(b)

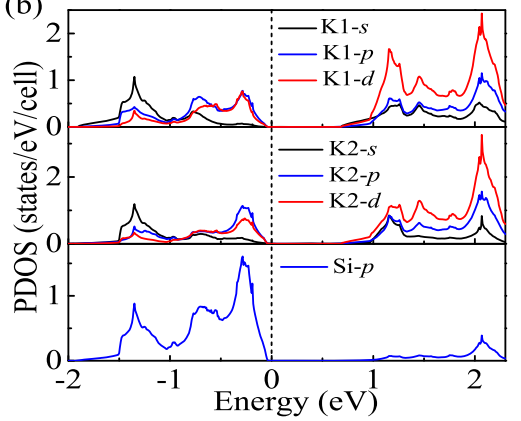

(e)

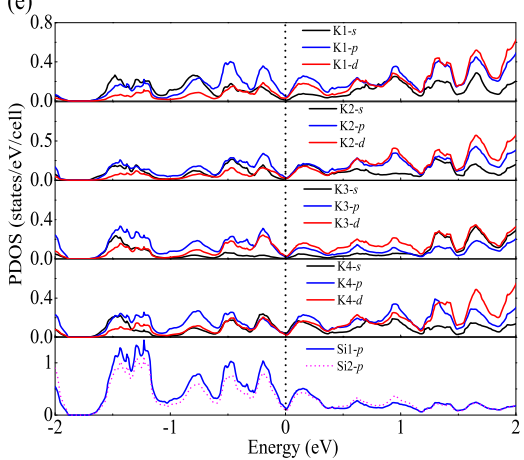

(h) 2

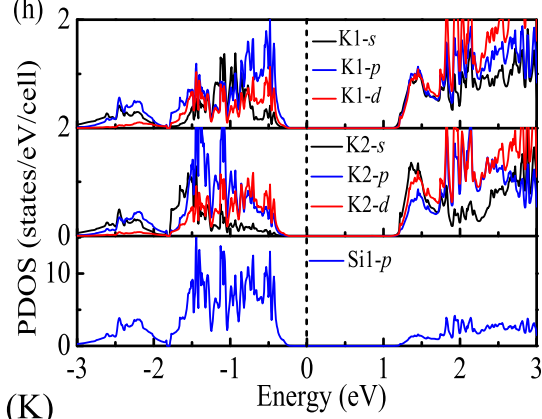

(K)

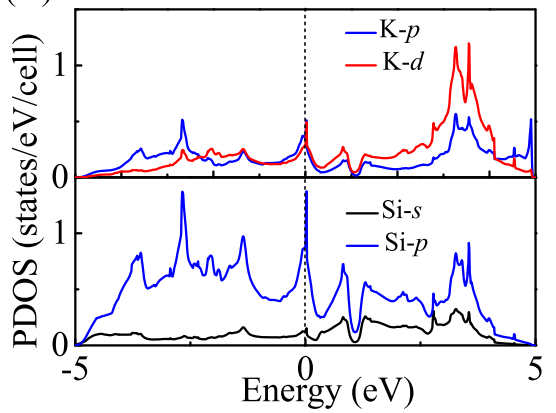

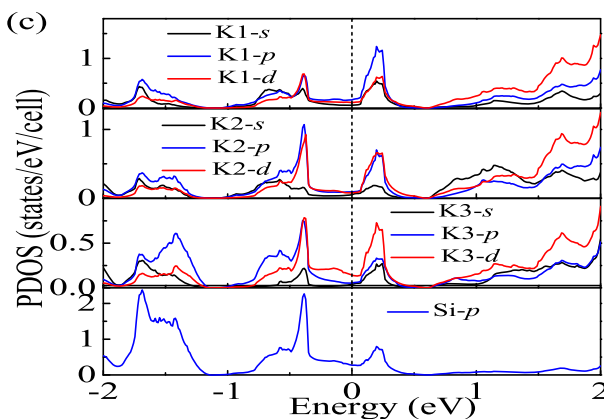

(f)

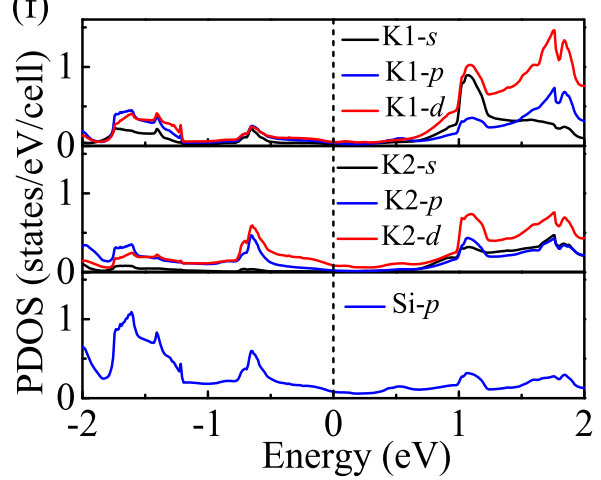

(i)
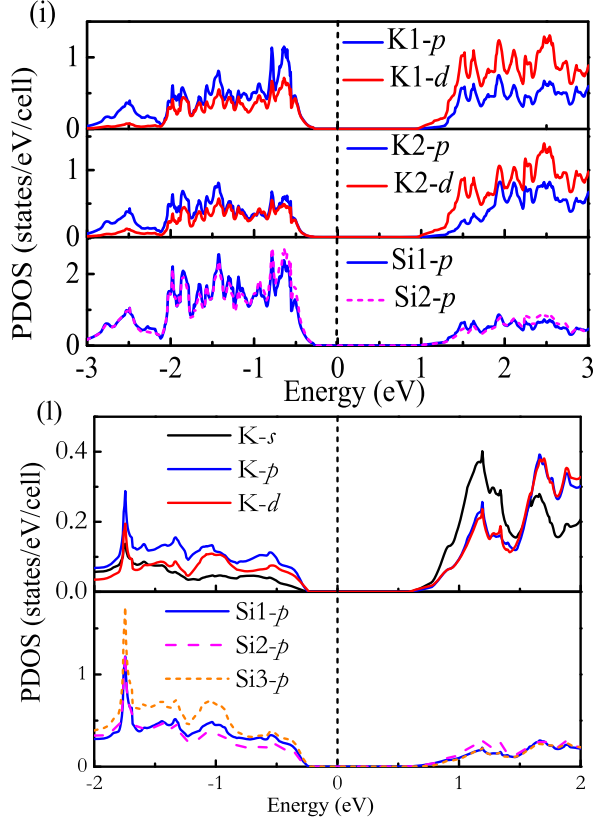

FIG. 5. Projected density of states of (a) $I 4 / m-\mathrm{K}_{4} \mathrm{Si}$ at $4 \mathrm{GPa}$, (b) $R-3 m-\mathrm{K}_{4} \mathrm{Si}$ at $16 \mathrm{GPa}$, (c) $C 2 / m-\mathrm{K}_{3} \mathrm{Si}$ at $6 \mathrm{GPa}$, (d) $R-3 m-\mathrm{K}_{5} \mathrm{Si}{ }_{2}$ at $9.0 \mathrm{GPa}$, (e) $P-1-\mathrm{K}_{2} \mathrm{Si}$ at $2.5 \mathrm{GPa}$, (f) $C m c m-\mathrm{K}_{2} \mathrm{Si}$ at $12.8 \mathrm{GPa},(\mathrm{g}) P-1-\mathrm{K}_{3} \mathrm{Si}_{2}$ at $1 \mathrm{GPa}$, (h) $I 4_{1} / a c d-\mathrm{KSi}$ at $2.2 \mathrm{GPa}$, (i) $C 2 / c-\mathrm{KSi}$ at $11 \mathrm{GPa},(\mathrm{j}) C 2 / m-\mathrm{KSi} 2$ at $5 \mathrm{GPa},(\mathrm{k}) F d-3 m-\mathrm{KSi}{ }_{2}$ at $18.5 \mathrm{GPa}$, and (1) $\mathrm{C} 2 / \mathrm{m}-\mathrm{KSi}_{3}$ at $0 \mathrm{GPa}$.

and the top of valence band. We also found that $P-1-\mathrm{K}_{2} \mathrm{Si}$ is a semimetal.

ELF maps the likelihood of finding an electron in the neighborhood space of a reference electron. In order to understand the bonding nature between the atoms in the $\mathrm{K}-\mathrm{Si}$ system, ELFs were calculated and shown in Fig. S6 of the supplementary material. One can conclude from ELF plots that all compounds predicted here show obvious ionic characteristics for $\mathrm{K}-\mathrm{Si}$ bonding, which in nature attributes to the large difference of electronegativity between the $\mathrm{K}$ atom and $\mathrm{Si}$ atom. As $\mathrm{Si}$ content increases, we can see the increasing ELF values between $\mathrm{Si}$ atoms that signal the strong covalent bonding. Different from the case of Ca-rich carbides in the $\mathrm{Ca}-\mathrm{C}$ system, ${ }^{13}$ there is no interstitial electron charge accumulation in the K-rich silicides predicted here, indicating that these K-rich compounds are not electrides.

To further explore the potential applications of novel semiconductors predicted here $\left(R-3 m-\mathrm{K}_{4} \mathrm{Si}, P-1-\mathrm{K}_{3} \mathrm{Si}_{2}\right.$, $P-43 n-\mathrm{KSi}, C 2 / m-\mathrm{KSi}_{2}$, and $C 2 / m-\mathrm{KSi}_{3}$ ), we calculated their dielectric properties. From the calculated dielectric functions, we can derive the optical absorption coefficients, which were 


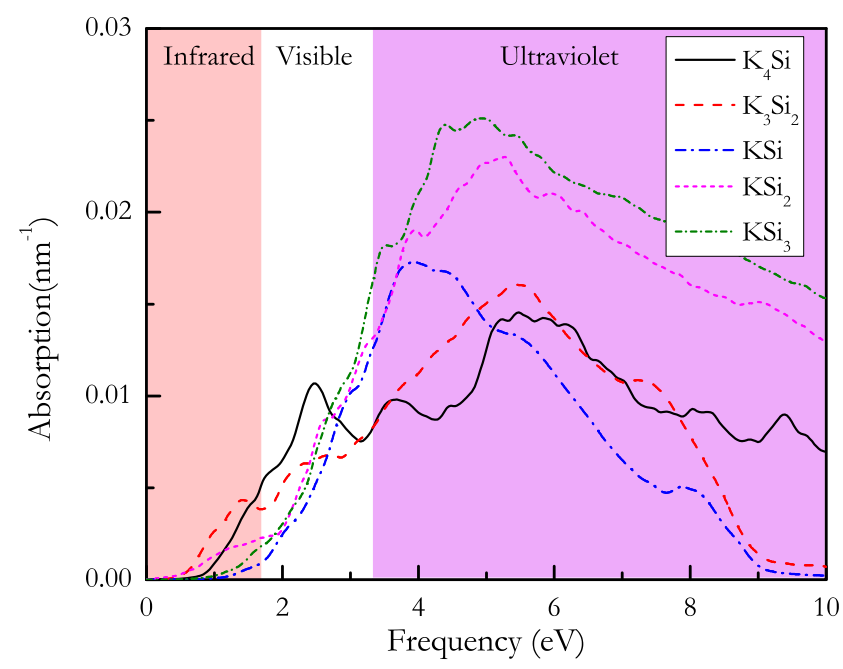

FIG. 6. The optical absorption spectrum of five semiconductors: $R-3 m-\mathrm{K}_{4} \mathrm{Si}$, $P-1-\mathrm{K}_{3} \mathrm{Si}_{2}, P-43 n-\mathrm{KSi}, C 2 / m-\mathrm{KSi}_{2}$, and $C 2 / m-\mathrm{KSi}_{3}$.

plotted in Fig. 6. The five predicted compounds exhibit considerably stronger absorption than diamond silicon in the infrared and the visible light range. $R-3 m-\mathrm{K}_{4} \mathrm{Si}$ has a pronounced absorption peak around $2.5 \mathrm{eV}$, suggesting that this structure has potential applications in the visible light range.

\section{CONCLUSION}

In summary, we have produced the first complete pressure-composition phase diagram for $\mathrm{K}-\mathrm{Si}$ compounds at pressures up to $30 \mathrm{GPa}$ by performing variable-composition evolutionary structure searching. The $\mathrm{K}-\mathrm{Si}$ system holds a rich thermodynamic phase diagram and presents a strong structural diversity. Eight novel K-Si compounds were identified and their structural phase transition sequences were also determined. With the increasing Si content, the form of polymerization of silicon atoms has undergone great changes, from the zero dimensional "isolated" silicon anions to Si dimers to novel $\mathrm{Si}_{4}$ group (zigzag, quadrangle, or tetrahedron) to one-dimensional chain to two-dimensional layers and to threedimensional open structures, presenting dimensional diversity. For two-dimensional silicon layers, silicon exhibits various patterns including " $4+8$ " rings, " $4+6$ " rings, and 8-membered rings, which essentially depends on the K:Si ratio and external pressure so as to overcome the potential barrier. The structural diversity leads to various manifestations of electronic structures which depend on the form of $\mathrm{Si}$ polymerization and $\mathrm{K}: \mathrm{Si}$ ratio. $\mathrm{K}-\mathrm{Si}$ bonding shows a character of mixed covalency and iconicity, while $\mathrm{Si}-\mathrm{Si}$ is of covalent character. Therefore, most compounds in the Si-rich side are semiconductors, except for the case when $\mathrm{K}$ forms its own bonding network. Semiconducting compounds can also form in the K-rich side only if the $\mathrm{Si}-p$ orbital is fulfilled and $\mathrm{K}$ is left with closedshell orbitals, which needs simultaneously both an appropriate $\mathrm{K}$ :Si ratio and Si polymerization. The excellent optical absorption properties of semiconducting compounds predicted here will evoke their potential applications on the utilization of the solar energy. We believe that the revealed compounds and chemistry in the $\mathrm{K}-\mathrm{Si}$ system are useful for future studies and applications and that our findings will ignite further experimental and theoretical studies on alkali metal-based IVA compounds.

\section{SUPPLEMENTARY MATERIAL}

See supplementary material for the crystal structures' information, phonon dispersion curves, energy band, and electronic localization function of the studied $\mathrm{K}-\mathrm{Si}$ system.

\section{ACKNOWLEDGMENTS}

The authors acknowledge support from the NSFC (Grant No. 11674131), Qing Lan Project, and the Priority Academic Program Development of Jiangsu Higher Education Institutions (PAPD). All the calculations were performed using the High Performance Computing Center of School of Physics and Electronic Engineering of Jiangsu Normal University.

${ }^{1}$ G. Profeta, M. Calandra, and F. Mauri, Nat. Phys. 8, 131-134 (2012).

${ }^{2}$ D. Connétable, V. Timoshevskii, B. Masenelli, J. Beille, J. Marcus, and B. Marcus, Phys. Rev. Lett. 91, 247001 (2003).

${ }^{3}$ D. Benson, Y. L. Li, W. Luo, R. Ahuja, G. Svensson, and U. Haussermann, Inorg. Chem. 52, 6402-6406 (2013).

${ }^{4}$ Y. L. Li, W. Luo, Z. Zeng, H. Q. Lin, H. K. Mao, and R. Ahuja, Proc. Natl. Acad. Sci. U. S. A. 110, 9289-9294 (2013).

${ }^{5}$ C. Zhang, J. Lan, H. Jiang, and Y. L. Li, J. Phys. Chem. C 120, 10137-10145 (2016).

${ }^{6}$ D. Y. Kim, S. Stefanoski, O. O. Kurakevych, and T. A. Strobel, Nat. Mater. 14, 169-173 (2015).

${ }^{7}$ M. Christensen, A. B. Abrahamsen, N. B. Christensen, F. Juranyi, N. H. Andersen, K. Lefmann, J. Andreasson, C. R. Bahl, and B. B. Iversen, Nat. Mater. 7, 811-815 (2008).

${ }^{8}$ M. Zeilinger, I. M. Kurylyshyn, U. Häussermann, and T. F. Fässler, Chem. Mater. 25, 4623-4632 (2013).

${ }^{9}$ Z. Zeng, Q. Zeng, N. Liu, A. R. Oganov, Q. Zeng, Y. Cui, and W. L. Mao, Adv. Energy Mater. 5, 1500214 (2015).

${ }^{10}$ Y. Lin, T. A. Strobel, and R. E. Cohen, Phys. Rev. B 92, 214106 (2015).

${ }^{11}$ Y. L. Li, W. Luo, X. J. Chen, Z. Zeng, and H. Q. Lin, Sci. Rep. 3, 3331 (2013).

${ }^{12}$ Y. L. Li, R. Ahuja, and H. Q. Lin, Chin. Sci. Bull. 59, 5269-5271 (2014).

${ }^{13}$ Y. L. Li, S. N. Wang, A. R. Oganov, H. Gou, J. S. Smith, and T. A. Strobel, Nat. Commun. 6, 6974 (2015).

${ }^{14}$ L. Wang, X. Huang, D. Li, Y. Huang, K. Bao, F. Li, G. Wu, B. Liu, and T. Cui, J. Chem. Phys. 144, 194506 (2016).

${ }^{15}$ H. Zheng, L. Wang, K. Li, Y. Yang, Y. Wang, J. Wu, X. Dong, C.-H. Wang, C. A. Tulk, J. J. Molaison, I. N. Ivanov, M. Feygenson, W. Yang, M. Guthrie, Y. Zhao, H.-K. Mao, and C. Jin, Chem. Sci. 8, 298-304 (2017).

${ }^{16}$ X. Jiang, J. Zhao, Y. L. Li, and R. Ahuja, Adv. Funct. Mater. 23, 5846-5853 (2013).

${ }^{17}$ J. Wu, H. Gao, K. Xia, D. Xing, and J. Sun, Appl. Phy. Lett. 111, 173904 (2017).

${ }^{18}$ H. Sung, W. H. Han, I. Lee, and K. J. Chang, Phys. Rev. Lett. 120, 157001 (2018).

${ }^{19}$ H. Okamoto, Bull. Alloy Phase Diagrams 11, 306-312 (1990).

${ }^{20}$ M. H. Braga, A. Dębski, and W. Gąsior, J. Alloys Compd. 616, 581-593 (2014).

${ }^{21}$ V. L. Chevrier, J. W. Zwanziger, and J. R. Dahn, J. Alloys Compd. 496, 25-36 (2010).

${ }^{22}$ R. Nesper and H. G. V. Schnering, J. Solid State Chem. 70, 48-57 (1987).

${ }^{23}$ A. Kuhn, P. Sreeraj, P. R. Pöttgen, M. Wilkening, and P. P. Heitjans, Angew. Chem., Int. Ed. 50, 12099-12102 (2011).

${ }^{24}$ N. Artrith, A. Urban, and G. Ceder, J. Chem. Phys. 148, 241711 (2018).

${ }^{25}$ U. Frank, W. Müller, and H. Schäfer, Z. Naturforsch. B 30, 10-13 (1975).

${ }^{26}$ Y. Kubota, M. C. S. Escano, H. Nakanishi, and H. Kasai, J. Appl. Phys. 102, 053704-053706 (2007). 
${ }^{27}$ D. Thomas, M. Zeilinger, D. Gruner, R. Hüttl, J. Seidel, A. U. B. Wolter, T. F. Fässler, and F. Mertens, J. Chem. Thermodyn. 85, 178-190 (2015).

${ }^{28}$ W. W. Tipton, C. R. Bealing, K. Mathew, and R. G. Hennig, Phys. Rev. B 87, 184114 (2013).

${ }^{29}$ S. Zhang, Y. Wang, G. Yang, and Y. Ma, ACS Appl. Mater. Inter. 8, 16761-16767 (2016)

${ }^{30}$ A. J. Morris, C. P. Grey, and C. J. Pickard, Phys. Rev. B 90, 054111 (2014).

${ }^{31}$ I. Valencia-Jaime, R. Sarmiento-Pérez, S. Botti, M. A. L. Marques, M. Amsler, S. Goedecker, and A. H. Romero, J. Alloys Compd. 655, 147-154 (2016).

${ }^{32}$ E. Busmann, Z. Anorg. Allg. Chem. 313, 90-106 (1961).

${ }^{33}$ L. H. Yang, C. D. Consorte, C. Y. Fong, J. E. Pask, E. Nabighian, S. M. Kauzlarich, and J. S. Nelson, Chem. Mater. 10, 4025-4029 (1998).

${ }^{34}$ J. Evers, G. Oehlinger, G. Sextl, and A. Weiss, Angew. Chem., Int. Ed. Engl. 23, 528-529 (1984).

${ }^{35}$ V. Quéneau, E. Todorov, and S. C. Sevov, J. Am. Chem. Soc. 120, 3263-3264 (1998).

${ }^{36}$ C. Cros, M. Pouchard, and P. Hagenmuller, J. Solid-State Chem. 2, 570-581 (1970).

37 J.-N. Chotard, W. S. Tang, P. Raybaud, and R. Janot, Chem. - Eur. J. 17, 12302-12309 (2011)

${ }^{38}$ J. S. Tse, S. Desgreniers, Z. Q. Li, and Y. Kawazoe, Phys. Rev. Lett. 89, 195507 (2002).

${ }^{39}$ T. Kume, T. Koda, S. Sasaki, H. Shimizu, and J. S. Tse, Phys. Rev. B 70, 052101 (2004).
${ }^{40}$ W. Zhang, Z. Y. Zeng, N. N. Ge, and Z. G. Li, Materials 9, 616 (2016).

${ }^{41}$ A. R. Oganov, A. O. Lyakhov, and M. Valle, Acc. Chem. Res. 44, 227-237 (2011).

${ }^{42}$ A. O. Lyakhov, A. R. Oganov, H. T. Stokes, and Q. Zhu, Comput. Phys. Commun. 184, 1172-1182 (2013).

${ }^{43}$ W. Zhang, A. R. Oganov, A. F. Goncharov, Q. Zhu, S. E. Boulfelfel, A. O. Lyakhov, E. Stavrou, M. Somayazulu, V. B. Prakapenka, and Z. Konôpková, Science 342, 1502-1505 (2013).

${ }^{44}$ J. Hafner, Comput. Phys. Commun. 177, 6-13 (2007).

${ }^{45}$ J. P. Perdew, K. Burke, and M. Ernzerhof, Phys. Rev. Lett. 77, 3865-3868 (1996).

${ }^{46}$ A. Togo, F. Oba, and I. Tanaka, Phys. Rev. B 78, 134106 (2008).

${ }^{47}$ K. Parlinski, Z. Q. Li, and Y. Kawazoe, Phys. Rev. Lett. 78, 4063-4066 (1997).

${ }^{48}$ P. Giannozzi, S. Baroni, N. Bonini, M. Calandra, R. Car, C. Cavazzoni, D. Ceresoli, G. L. Chiarotti, M. Cococcioni, I. Dabo, A. Dal Corso, S. de Gironcoli, S. Fabris, G. Fratesi, R. Gebauer, U. Gerstmann, C. Gougoussis, A. Kokalj, M. Lazzeri, L. Martin-Samos, N. Marzari, F. Mauri, R. Mazzarello, S. Paolini, A. Pasquarello, L. Paulatto, C. Sbraccia, S. Scandolo, G. Sclauzero, A. P. Seitsonen, A. Smogunov, P. Umari, and R. M. Wentzcovitch, J. Phys. Condens. Matter. 21, 395502 (2009).

${ }^{49}$ A. D. Becke and K. E. Edgecombe, J. Chem. Phys. 92, 5397-5403 (1990).

${ }^{50}$ U. Frank, W. Müller, and H. Schäfer, Z. Naturforsch. B 30, 1-5 (1975).

${ }^{51}$ D. Gilde, Z. Anorg. Allg. Chem. 284, 142-143 (1956).

${ }^{52}$ J. B. Friauf, J. Am. Chem. Soc. 49, 3107-3114 (1927). 